\title{
Percepción y realidad de la criminalidad en el Tolima durante la República Liberal
}

\section{Perception and reality of Crime in Tolima During the Liberal Republic}

\author{
Gilberto Parada \\ Universidad del Tolima, Colombia. \\ geparadag@ut.edu.co|https://orcid.org/0000-0002-7832-9733 \\ Recibido: 25 de marzo de 2020. Aprobado: 08 de Julio de 2020 \\ DOI:10.25100/hye.v16i55.10777 \\ Artículo de investigación
}

¿Cómo citar este artículo? / How to quote this article?

Parada, Gilberto. "Percepción y realidad de la criminalidad en el Tolima durante la República Liberal”. Historia y Espacio, vol. 16 n 55 (2020):73-95.

Doi.org/10.25100/hye.v16i55.10777 


\title{
Resumen
}

Este artículo examina algunos delitos violentos ocurridos en el departamento colombiano del Tolima entre 1930 y 1946 para replantear la percepción que la dirigencia social tolimense tenía de la criminalidad. Se afirma que algunos delitos que han sido asociados a la violencia política en el Tolima después de 1946 se registraron también durante la República Liberal. A partir del análisis de estadísticas y causas criminales, se reconfigura la idea de la criminalidad y se esbozan las principales características del sistema judicial y de la cultura jurídica de los gobiernos liberales, los cuales implementaron nuevas técnicas para contener una presunta escalada delictiva.

Palabras clave: historia del Tolima (Colombia), crimen, violencia, justicia.

\begin{abstract}
This article examines some violent crimes that occurred in the Colombian department of Tolima between 1930 and 1946, to rethink the perception that Tolima society had of criminality. It is stated that some crimes that have been associated with political violence in Tolima after 1946 were also recorded during The Liberal Republic. From the analysis of statistics and criminal cases, the idea of criminality is reconfigured and the main characteristics of the judicial system and legal culture of liberal governments are outlined, which implemented new techniques to contain the alleged criminal escalation.
\end{abstract}

Keywords: Tolima's History (Colombia), Crime, Violence, Justice. 


\section{Introducción}

"Esa noche los diablos iban a dar candela". Con esta amenaza un campesino sentenciaba a su compañera a una agresión brutal que desencadenaría su muerte. Los hechos acontecieron en 1937: la mujer fue amarrada, abusada, herida y golpeada, casi hasta morir. Logró escapar de su propia casa y pudo denunciar al autor de la golpiza. Una vez enterada, la policía condujo al agresor ante el juez, solo le impusieron una caución y quedó libre. No obstante, el hombre la golpeó nuevamente y, a los pocos días, ella falleció. La atención que se les preste a los aspectos escandalosos del crimen puede apoyar la interpretación de las formas violentas mediante las cuales las clases populares resolvían sus pleitos domésticos. La investigación de los documentos judiciales, además de exponer las narrativas subjetivas de los implicados, también descubre los entramados circunstanciales de la sociedad y del colectivo ${ }^{1}$. Así, esta investigación busca entender las complejas relaciones sociales en las que ocurre la violencia criminal en el departamento del Tolima - centro colombiano - durante el periodo comprendido entre 1930 y 1946.

Uno de los análisis más destacados de la historia política del Tolima afirma que su historia estaba "llena de drama" ${ }^{2}$ ", y este punto de vista trágico ha sido el dominante al caracterizar la semblanza histórica del departamento ${ }^{3}$. Esta idea se sustenta en el hecho histórico que indica que allí se gestó la gran tragedia nacional que se conoce como la Violencia. Además, la mayor parte de los análisis cuyo tema central es la violencia de mediados de siglo XX colombiano han priorizado la perspectiva política, mientras que el estudio de la dimensión delincuencial de la violencia ha sido considerado un epifenómeno de la dinámica política ${ }^{4}$.

De ahí que este artículo analice algunos delitos como el homicidio, las lesiones personales, los abusos sexuales y las formas violentas del bandidaje. De este último delito se observa cómo generó expediciones punitivas que encabezaron agentes de policía de dudosa reputación ${ }^{5}$. También se alude a los homicidios y a los abusos contra las mujeres y los niños, pero se advierte que no todos los delitos generaban violencia; los hurtos podían desestabilizar la seguridad económica de las víctimas, aunque no necesariamente eran violentos; de ahí que en este artículo se habla del abigeato que cometían bandas organizadas y que lo perpetraban en circunstancias violentas. Cabe mencionar que, en algunos casos, despojos de tierras (delito conocido por el derecho civil) en forma conexa

\footnotetext{
${ }^{1}$ Hermes Tovar Pinzón, La batalla de los sentidos. Infidelidad, adulterio y concubinato a fines de la Colonia (Bogotá: Universidad de los Andes, 2012), 11.

2 James Henderson, Cuando Colombia se desangró. Un estudio de la Violencia en metrópoli y provincia (Bogotá: El Áncora, 1984), 40.

${ }^{3}$ Robert A, Karl, Forgotten Peace. Reform, Violence, and the Making of Contemporary Colombia (Oakland: University of California Press, 2017), 6-8.

${ }^{4}$ Sobre el particular apunta Malcolm Deas: “[...] el fenómeno colombiano no es en absoluto sencillo. No se puede dar cuenta de los homicidios en Colombia, ni desecharlos, ni explicarlos [...]”. Malcolm Deas y Fernando Gaitán Daza, Dos ensayos especulativos sobre la violencia en Colombia (Bogotá: Fonade/DNP, 1995), 9.

${ }^{5}$ Germán Guzmán, Orlando Fals Borda y Eduardo Umaña Luna, La violencia en Colombia, T. I y T. II (Bogotá: Aguilar/Altea/Taurus/Alfaguara, 2010), 40.
} 
condujeron a homicidios que no conocía inicialmente la justicia penal ${ }^{6}$. Otros delitos, como las riñas, entran en la categoría de las contravenciones policiales, por lo que, a primera vista, podrían ser comportamientos más tolerados por las autoridades; sin embargo, posteriormente podían causar la muerte de las víctimas debido a las secuelas de los traumas físicos y entonces se convertían en homicidios. También en los abusos sexuales mediaba la violencia física y, en los casos de delitos políticos, el uso de la fuerza es una constatación de la violencia.

También este artículo busca reasignar la posición dada a los delitos violentos por parte de algunos autores, quienes analizan la violencia política y, por tanto, los asumen como parte reconocible de la criminalidad que apareció durante la Violencia. La historiografía que reúne a esos analistas ubicó la criminalidad en el período posterior al que la historia política conoce como la República Liberal situándola en "La Violencia" de los años cincuenta ${ }^{7}$. Un ejemplo destacado es la afirmación que hacen Gonzalo Sánchez y Donny Meertens en el libro Bandoleros, gamonales y campesinos:

"En el siglo XX, se hizo presente una dimensión nueva del conflicto armado que lo diferenciaba de las guerras civiles del siglo XIX: mientras en estas últimas se trataba predominantemente entre ejércitos de hombres que arrojaban víctimas masculinas, durante la Violencia se involucraba en mayor medida a la población civil y por primera vez las víctimas se distribuían sistemáticamente en ambos sexos."

Enfáticamente, esta investigación matiza la imagen que los coetáneos se habían formado de la criminalidad, ya que entre 1930 y 1946 cundió entre los tolimenses una percepción del crimen lo suficientemente difundida como para hablar de una escalada delictiva sin precedentes. Para atenuar dicha imagen, este trabajo se apoya en las estadísticas criminales del departamento en comparación con los datos nacionales. De esta manera, se puede argumentar que en los años del Gobierno liberal los delitos violentos no aumentaron como lo afirmaba la opinión general. Por el contrario, tales indicadores tendieron a estabilizarse e incluso a disminuir en ciertos años, como se verá más adelante.

Las fuentes para este trabajo son estadísticas criminales, informes de gobierno, leyes, jurisprudencia y expedientes judiciales. En definitiva, el fundamento de este trabajo encaja en la historia social de la justicia ${ }^{9}$, enfocado desde una perspectiva crítica ${ }^{10}$. Para controvertir la idea de un ascenso en los indicadores del delito el artículo se organiza en tres apartados. En primer lugar, se describe el funcionamiento de la justicia penal y las

\footnotetext{
${ }^{6}$ Tribunal Superior de Ibagué, "Sumario contra Simón Rubiano, Manuel Antonio Camacho y otros, por el homicidio de Santos Padilla”, Ibagué, 1941, Archivo Histórico de Ibagué (AHI), Sección República, Fondo criminales; Darío Fajardo, Violencia y desarrollo. (Transformaciones sociales en tres regiones cafeteras del Tolima, 1936-70) (Bogotá: Fondo Editorial Suramérica, 1979), 42.

${ }^{7}$ Marco Palacios, Violencia pública en Colombia, 1958 - 2010 (México: FCE, 2012); Paul Oquist, Violencia, conflicto y política en Colombia (Bogotá: IEC/Biblioteca Banco Popular, 1978).

${ }^{8}$ Gonzalo Sánchez y Donny Meertens, Bandoleros, gamonales y campesinos. El caso de la Violencia en Colombia (Bogotá: El Áncora, 2006), 18.

9 José Ramón Narváez H, Historia social del derecho y de la justicia (México: Porrúa, 2007), X-XII.

${ }^{10}$ Marcos Fernández Labbé, "Sangre por sangre: la retórica judicial y la veracidad documental como problema heurístico en las solicitudes de indulto", Justicia, poder y sociedad en Chile: recorridos históricos, eds. Tomás Cornejo C. y Carolina González U. (Santiago: Ediciones Universidad Diego Portales, 2007), 220.
} 
dinámicas doctrinales entre los agentes de la justicia; de hecho, se observa que algunas pautas de comportamiento popular fueron asimiladas como circunstancias de los hechos delictivos. En segundo lugar, disipa la idea de la escalada criminal al poner en debate la percepción del delito con las estadísticas criminales; por último, subraya las condiciones sociales de los agentes del crimen, enseñando las relaciones de poder que surgieron al momento de activarse la justicia penal y pone la atención en los criminales y en las víctimas.

\section{EI sistema de justicia penal y la cultura jurídica en el Tolima}

Ya para la época, la máxima instancia de justicia en el Tolima era el Tribunal Superior, conformado por cinco magistrados y con sede en Ibagué. También operaban dos juzgados especializados ubicados en la capital del Tolima y 16 juzgados de circuito, situados en los municipios de Ambalema, Espinal, Fresno, Guamo, Honda, Líbano, Melgar, Purificación y Villahermosa. En los municipios que no contaban con juzgados propios, las denuncias penales eran recibidas por los alcaldes e inspectores de Policía, que conocían en primera instancia y, si la causa lo ameritaba, era remitida a los juzgados del correspondiente circuito. A su vez, los juzgados de circuito y especializados remitían al tribunal las apelaciones que, en contadas ocasiones, se llevaban a la Corte Suprema de Justicia en Bogotá.

Todo parece confirmar que un aire de cientificidad inspiraba el trabajo de los jueces, peritos y abogados (doctores y leguleyos), pues los alegatos, las pruebas periciales, los peritajes y los fallos judiciales se volvían cada vez más sofisticados. Para tener mayor validez procesal, el discurso jurídico se llenó de vocablos científicos provenientes de la biología y los jueces sustentaron sus autos y sentencias citando autores que hacían eco del positivismo penal ${ }^{11}$. En tanto que, en los poblados más remotos, los alcaldes, policías, tinterillos y leguleyos acudían a un saber empírico.

En ese ambiente de cientificidad, el positivismo penal tuvo un impacto profundo en la cultura jurídica colombiana en la década de $1930^{12}$, tanto que inspiró la redacción de códigos penales, de procedimiento penal y de policía durante la República Liberal ${ }^{13}$. En uno de los rasgos más destacados, el positivismo penal concibió al delincuente como un anormal potencialmente peligroso. En este orden de ideas, el proceso penal se llenó de artificios científicos para determinar los hechos y las responsabilidades criminales, así como la peligrosidad de los delincuentes. Las pruebas testificales fueron las más recurrentes a la hora de probar las situaciones delictivas; las pruebas periciales

\footnotetext{
${ }^{11}$ Gilberto Enrique Parada García, "Derecho, positivismo y sociedad. El caso de la Facultad de Derecho (1900-1940)", en Economía, lenguaje, trabajo y sociedad. Colección del Sesquicentenario Universidad Nacional de Colombia. T. 1, 1/3, eds. Estela Restrepo Zea y otros (Bogotá: Universidad Nacional de Colombia, 2017), 82.

12 Parada García, "La historicidad del delito en la manualística del Derecho penal colombiano", Vniversitas vol. 67, n. ${ }^{\circ} 137$ (nov. 2018). doi:10.11144/Javeriana.vj137.hdmp.

${ }^{13}$ En 1936 se expidió el Código Penal, en 1938 apareció el Código de Procedimiento Penal, el Código de Policía del Tolima data de 1935; entre 1936 y 1940 son dictados varios decretos que pretendían contener la criminalidad. Así mismo, en 1934 se reglamentó el sistema carcelario y penitenciario.
} 
confirmaron los hechos delictivos ${ }^{14}$. Por ejemplo, los dibujos de las armas, en procesos por homicidios, asesinatos o heridas, ya existían como acervo probatorio en Colombia desde los años sesenta del siglo XIX, pero fue durante los años treinta del siglo XX que se emplearon las fotografías como pruebas. En un caso de violación, el Tribunal ordenó el acopio de pruebas como la fotografía, el dibujo forense y la datación astronómica para averiguar si, en la noche del delito, la denunciante pudo haber visto bajo la luz de la luna la consumación del acto (Ver figuras 01 y 02).

\section{Figura 01.}

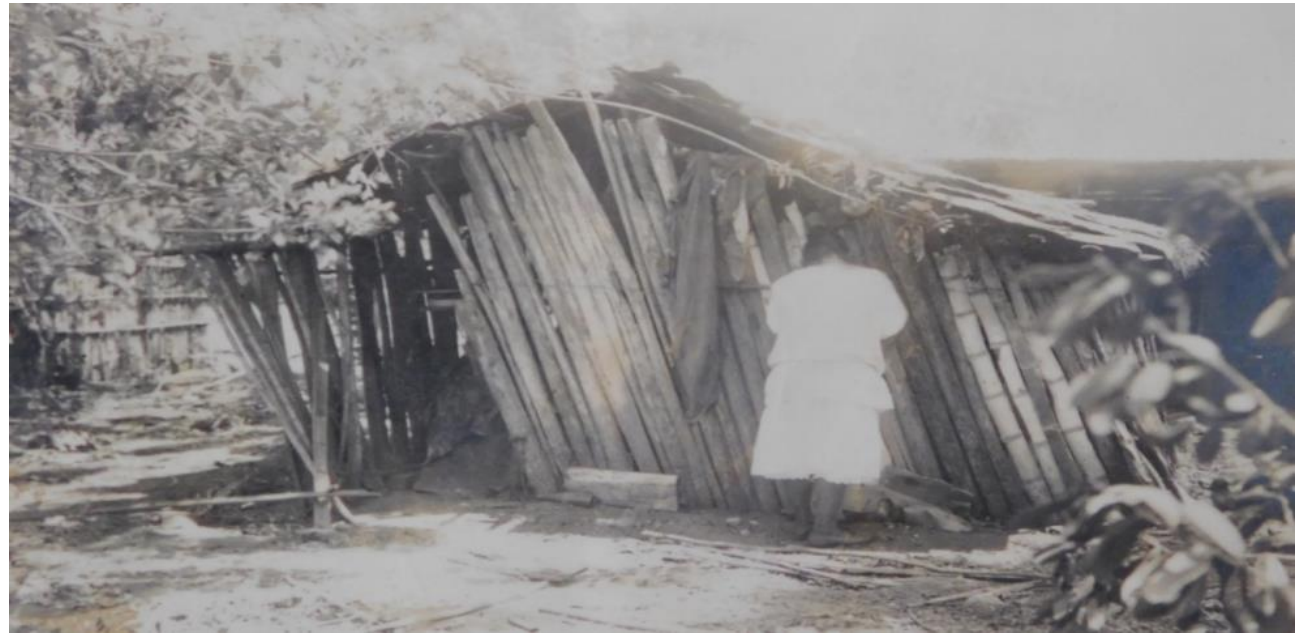

Fuente: Fotografía forense tomada por Juan García Moreno. Tribunal Superior de Ibagué, Causa contra Manuel Domingo Suárez y Betsabé Herrera por el delito de fuerza y violencia, y corrupción, 1928, AHI, Ibagué, folio 82 .

\section{Figura 02.}

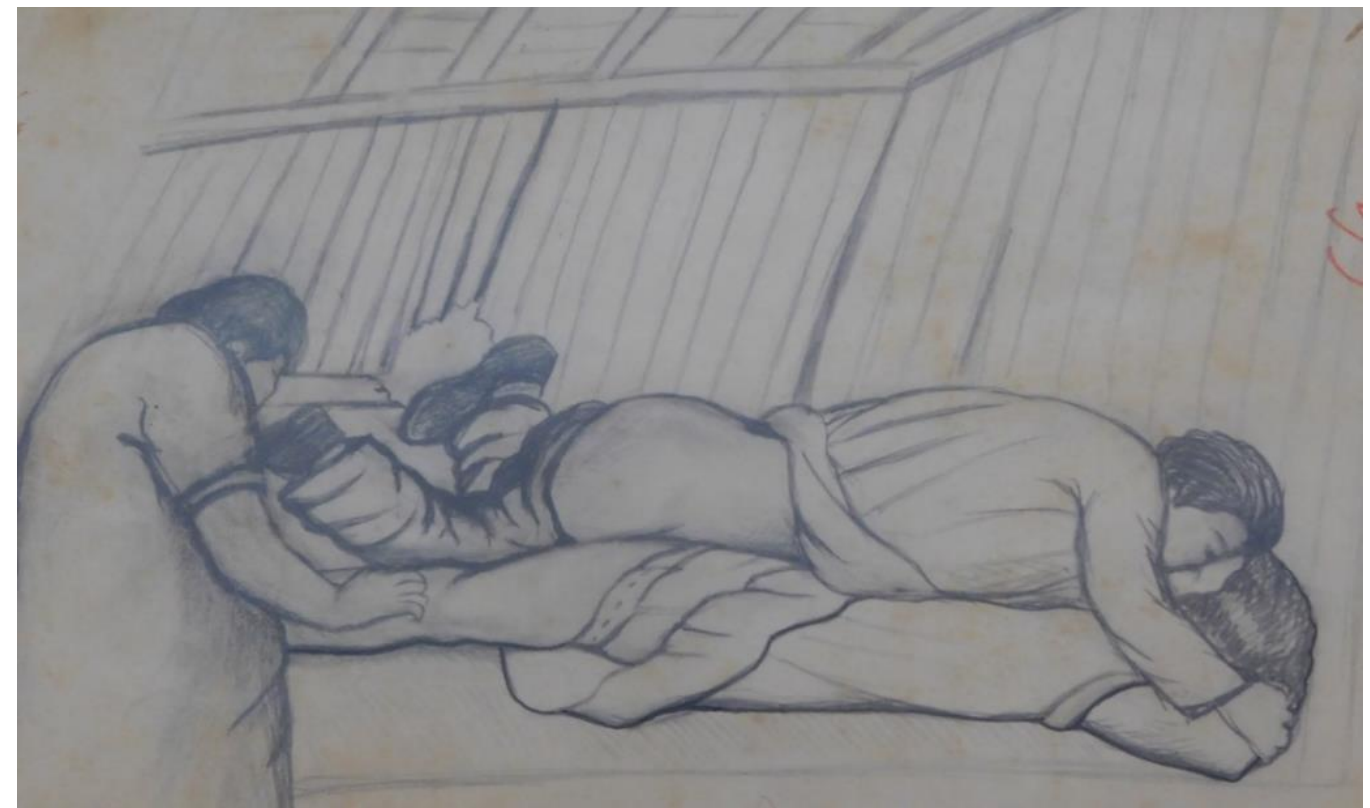

\footnotetext{
${ }^{14}$ Jorge Ortega Torres, Código penal y de procedimiento penal. Con notas, concordancias, jurisprudencia de la Corte Suprema y del Tribunal de Bogotá y las últimas leyes complementarias (Bogotá: Librería Colombiana Camacho Roldán \& Cía., 1947), 235.
} 
Fuente: Dibujo forense elaborado como prueba pericial. Tribunal Superior de Ibagué, Causa contra Manuel Domingo Suárez y Betsabé Herrera por el delito de fuerza y violencia, y corrupción, 1928, AHI, Ibagué, folio 99 .

En cuanto a la cultura jurídico-penal, el positivismo condicionó los fallos de los magistrados y destacó que el consumo de alcohol era un trauma degenerativo que giraba en torno al crimen. Así, pues, uno de los conceptos de mayor trascendencia derivados del positivismo fue el de la peligrosidad ${ }^{15}$. Un fallo jurisprudencial proferido por la Sala Penal del Tribunal Superior se basó en los planteamientos de la escuela positivista, cuando desestimó los elementos atenuantes de Rafael María Bellón, cuya defensa pretendió obtener del Tribunal una rebaja de la pena por el delito de homicidio. De manera precisa, la influencia del positivismo en la jurisprudencia del Tribunal aparece en una cita del médico peruano Carlos Bambarén ${ }^{16}$ que el magistrado ponente Raúl Carrera tomó para acentuar la peligrosidad de Bellón: Los elementos subjetivos de la PELIGROSIDAD, hay que buscarlos en la genealogía del delincuente. EN SU BIOTIPOLOGÍA, en su carácter y en sus manifestaciones del sentido moral, que sufre metamorfosis según un conjunto de circunstancias que conviene puntualizar en cada caso particular ${ }^{17}$.

Luego de presentar la idea general de Bambarén, el magistrado Carrera buscó las causas del delito cometido por Bellón en su biotipología, por lo que persuadió al resto de la sala de magistrados de la peligrosidad de este procesado, cuyo padre tenía antecedentes criminales: [...] se deduce que las causas inmediatas y remotas del hecho delictuoso que se le imputa, radican en su progenitor, a quien se describe como un alcohólogo, agresivo y grosero con pasado judicial criminoso ${ }^{18}$. Sin embargo, el consumo de licor no era un hecho aislado, o que se limitaba a los campesinos y jornaleros, ya que era común que policías y militares fueran vistos borrachos en el ejercicio de sus funciones y llegaban incluso a cometer crímenes en esos estados de ebriedad ${ }^{19}$.

En efecto, la ebriedad fue una circunstancia que marcó la perpetración de los delitos de sangre. Para precisar, en 1939, el 72,2\% de este grupo de delitos fue cometido en el Tolima bajo la influencia del alcohol ${ }^{20}$. Este promedio fue inferior al de Antioquia, Cundinamarca, Boyacá, Valle y Caldas, pero superó al de los departamentos de la costa atlántica (ver Mapa 1). Entre las autoridades, el consumo del licor desencadenó visiones

\footnotetext{
${ }^{15}$ Ortega Torres, Código penal, 27.

${ }^{16}$ Carlos Bambarén fue pionero en la medicalización del delito, pues concibió el hecho criminoso como la sumatoria de causas patológicas como la demencia, la epilepsia y el alcoholismo. Carlos Aguirre, "Crime, Race, and Morals: The Development of Criminology in Peru 1890-1930", Crime, History \& Societies 2, n. 2 (1998): 85. doi:10.4000/chs.968

17 Tribunal Superior de Ibagué, "Se confirma, modificando en parte el fallo de primera instancia dictado en el proceso contra Rafael María Bellón Sepúlveda, por el homicidio perpetrado en la persona de Luis Alarcón” (Mayúsculas del documento). Crónica Judicial (s. d.) (1941): 1025.

${ }^{18}$ Tribunal Superior de Ibagué, "Se confirma, modificando en parte el fallo de primera instancia dictado en el proceso contra Rafael María Bellón Sepúlveda, por el homicidio perpetrado en la persona de Luis Alarcón." Crónica Judicial (s. d.) (1941): 1025.

19 Tribunal Superior de Ibagué, "Juicio contra Ramón Vesga y José Martínez, por el homicidio y delitos contra funcionario público”, Ibagué, 1941, AHI, Ibagué, S. República, F. Criminales.

${ }^{20}$ Dirección Nacional de Estadística, Anuario general de Estadística (Bogotá: Imprenta Nacional, 1940): 343.
} 
contrapuestas; en la justicia penal reinaba la imagen negativa y se aspiraba a la prohibición; de otra parte, para el gobernador la imagen era optimista dado que, para el año fiscal de 1933, la suma recaudada en las rentas departamentales generada por las bebidas alcohólicas representó más del $46 \%$ del total, lo que representó un superávit para ese $a \tilde{n} o^{21}$.

Pero, definitivamente, el consumo de alcohol fue uno de uno de los aspectos que la justicia ansiaba determinar para inculpar o atenuar la responsabilidad penal ${ }^{22}$. También los implicados apelaban a la ebriedad como condición de atenuación de un delito. Unos bandidos que asolaban la compañía del cable aéreo señalaron en sus declaraciones que no pudieron haber cometido los hurtos, pues estaban de parranda, bebiendo y jugando en la plaza del pueblo; por tanto, no tenían conciencia del delito de que se les acusaba: [...] en Mariquita en las últimas ferias, el día jueves por la noche anduvimos desde las siete hasta las diez tomándonos unos tragos, y el día viernes nos encontramos en una cantina de una esquina donde estuvimos tomando trago desde las nueve hasta las diez de la mañana, charlamos bebiendo sin tratar nada y solo tomando trago $^{23}$.

Otro caso ilustra cómo el consumo de alcohol, entre los miembros de una parentela, sirvió para explicar un homicidio perpetrado en medio de la celebración y la juerga $^{24}$. Luego de ser indagados veinte allegados de la víctima, no se imputaron cargos al principal sospechoso de este homicidio. Importa destacar la manera en que los indagados, al ser interrogados por el policía, primero, y luego en el juzgado municipal, señalaron no haber tenido mayor contacto con el occiso y precisaron que la víctima estaba bajo los efectos del alcohol la noche en que falleció; ninguno de los sindicados manifestó estar ebrio; más aún, adujeron que la muerte de la víctima se dio en medio del silencio y la oscuridad, por lo que no sabían quién o quiénes fueron los causantes del deceso.

\footnotetext{
${ }^{21}$ Heriberto Amador, Mensaje del gobernador del departamento a la honorable Asamblea en sus sesiones ordinarias de 1934 (Ibagué: Imprenta Departamental, 1934), 22.

22 Departamento del Tolima, Código de Policía (Ordenanza 30 de 1932) (Ibagué: Imprenta Departamental, 1935), artículos 141 a 151.

${ }^{23}$ Tribunal Superior de Ibagué, "Sumario. En averiguación del responsable o responsables del delito de homicidio con caracteres de asesinato perpetrado en la persona de Gabriel Chávez, el día 22 de mayo de 1933”, Ibagué, 1933, AHI, Ibagué, S. República, F. Criminales, f. 56 verso.

${ }^{24}$ Tribunal Superior de Ibagué, "Sumario contra Félix Leal por el homicidio de Julián Vargas, el 28 de marzo de 1933”, Ibagué, 1933, AHI, Sección República, Fondo criminales, ff. 3-31.
} 


\section{Figura 03. Comparativo de los delitos de sangre cometidos bajo estado alcohólico y en sobriedad, Colombia (1939)*}

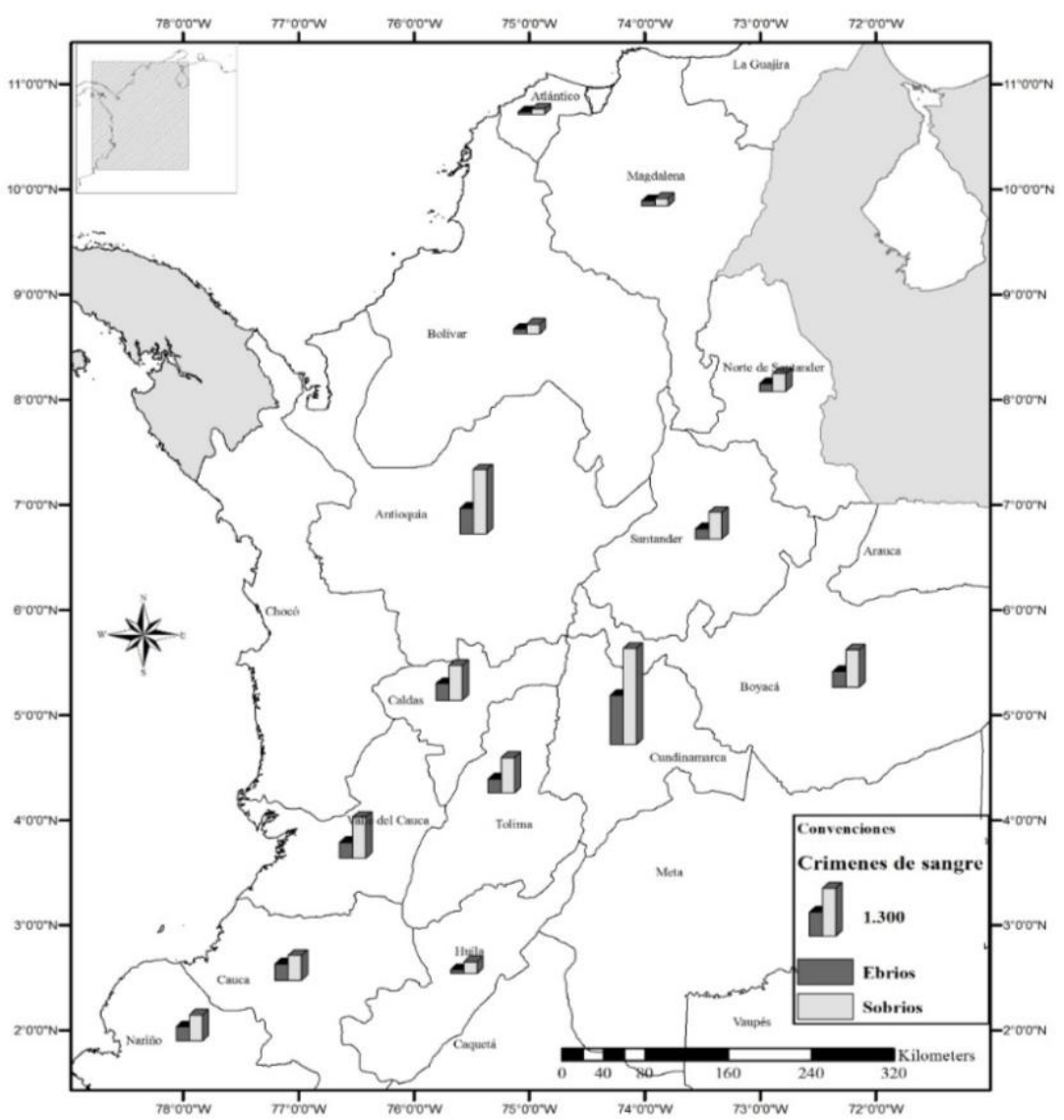

* Proporción de delitos de sangre cometidos en el año de 1939 por departamentos. Se aprecian los que fueron cometidos bajo la influencia del alcohol y los que no; se excluyen de esta presentación los llamados territorios nacionales porque no representan un valor que incida en las estadísticas. Elaboración propia con base en: Dirección Nacional de Estadística, Anuario general de Estadística (Bogotá: Imprenta Nacional, 1940): 343 .

Ahora bien, se podría decir que los vínculos sociales sobrepasaban el efecto de la ley, ya que la aldea campesina optaba por recurrir a la forma más primitiva de justicia, es decir, a la venganza. Una población víctima del abigeato, presionada por el acecho de los cuatreros, se vio compelida a pedir de la autoridad política facultades de policía judicial; en 1939, en la población de Chaparral, dos agentes de policía ad honorem fueron comisionados para detener a Filomeno Oviedo y a Santos González, integrantes de una peligrosa banda de cuatreros dedicados a "robos y tropelías" que tenían azotado el sur del Tolima. Evilario Ospina y Juan Moreno eran unos labradores víctimas de robos y, además, vecinos de los cuatreros, por lo que acudieron ante el alcalde para fungir como policías rurales; una vez nombrados buscaron a otros campesinos y con la ayuda de un delator capturaron a Filomeno Oviedo y le dieron muerte por desmembramiento. En la tarde del 15 de noviembre de 1939, Oviedo, un hombre peligroso, yacía en una casa en el campo, mascando coca y chicote cuando huyó al escuchar las voces de los policías. Durante la fuga se presentó una lucha y en medio de la oscuridad Oviedo, el matarife, [...] sacó la peinilla y se nos vino encima furiosamente echándonos machete [...] Allí se 
volvió una chichera, yendo dar hasta el monte, defendiéndonos los más con palos que llevábamos y como resultado Filomeno Oviedo cayó al suelo herido de muerte ${ }^{25}$. Es en este contexto que se hace casi imposible distinguir el límite moral entre el delincuente y el policía.

Un ámbito de la cultura jurídica local siguió los principios deterministas del positivismo penal. Por ejemplo, las autoridades reconocieron a un testigo por sus rasgos físicos y de ahí concluyeron una personalidad moral que, aunque humilde, era proclive a la mentira ${ }^{26}$. De Felipe González, un hombre cercano a Oviedo, conjeturaron la falsedad de su testimonio porque tenía un brillo en los ojos que lo acompaña y se hacía más intenso cuando mentía en cada declaración. Se trataba de un hombre analfabeta, moreno, menudo, "sonso" y de "ojos expresivos", además, vestía humildemente y era un individuo que tiene rarezas como mascar coca.

Los detalles físicos, los rasgos sociales, las actitudes emocionales, el vestuario y el parentesco dieron un marco de referencia para encuadrar a los ladrones. Además, en el esquema interpretativo positivista del delito, el contexto social era asumido como la causa principal de la delincuencia en la región; al roce cotidiano con personas indeseadas se le achacó el origen de la personalidad delictiva. Un testigo afirmó del ladrón de ganado que: lo conocí pequeñito y fuimos amigos, y en un principio era un hombre honrado y muy bueno, pero ahora últimamente adquirió la fama de ladrón y de hombre peligroso, seguramente debido a las malas compañías, y de esta manera el delincuente era un sujeto temido y a la vez admirado por la comunidad campesina ${ }^{27}$.

En síntesis, algunos valores populares fueron considerados por los operadores jurídicos como incentivos para la violencia criminal. El consumo de bebidas embriagantes y las fiestas dieron pie a los entendidos para explicar la violencia criminal desatada en el Tolima y, con el arribo de la cientificidad jurídico penal, los inspectores de policía, alcaldes y algunos jueces continuaron delineando la personalidad delictiva de acuerdo con ciertos comportamientos morales de la población, que se enfrascaba en vindictas personales para alcanzar lo que entendía por justicia.

\section{Las percepciones sobre el crimen y la violencia en el Tolima}

Son pocas las razones que llevaron a pensar que el Tolima experimentó desde 1930 una escalada en la criminalidad ${ }^{28}$. En principio, los gobernadores y la gente del común arguyeron que tal espiral delictiva fue causada por el hecho de que tanto la policía como el sistema carcelario del departamento eran deficitarios, aunque los liberales habían

\footnotetext{
25 Tribunal Superior de Ibagué, "Sumario contra Juan Moreno, Evilario Ospina y otros por homicidio", Ibagué, 1939, AHI, Ibagué, S. República, F. Criminales, f. 8 verso.

${ }^{26}$ Tribunal Superior de Ibagué, "Sumario contra Juan Moreno, Evilario Ospina y otros por homicidio", Ibagué, 1939, AHI, Ibagué, S. República, F. Criminales, f. 14 verso.

27 Tribunal Superior de Ibagué, "Sumario contra Juan Moreno, Evilario Ospina y otros por homicidio", Ibagué, 1939, AHI, S. República, F. Criminales, f. 56 verso.

${ }^{28}$ E. P. Thompson advierte que el contraste entre las perspectivas de análisis cuantitativo y cualitativo ofrece un balance más armónico con la realidad del pasado criminal. E. P. Thompson, Agenda para una historia radical (Barcelona: Crítica, 2000), 14.
} 
tomado medidas como el establecimiento de la colonia penal de Ataco en 1932 y habían expedido el código de policía en 1935. Esta sensación puede corroborarse con la política criminal de los gobiernos liberales entre 1930 y 1946, que introdujo la defensa social como noción que aludía a la prevención de los delitos (defensa preventiva) y la represión de los delitos (defensa represiva) ${ }^{29}$. De acuerdo con esta idea, el control de la criminalidad anduvo entre la protección de las libertades individuales y la eficiencia para atrapar, juzgar y encarcelar; de suerte que se generó en la sociedad una expectativa de inseguridad que debía ser saciada a través de la política criminal ${ }^{30}$.

Las ideas de los gobernadores eran contradictorias sobre la criminalidad. Por ejemplo, en cuanto al orden público, expresaron que la década de 1930 fue pacífica, sobre todo si se la compara con la década de 1920 en la que las manifestaciones violentas tuvieron que ver con la protesta social ${ }^{31}$. Esa paz política fue relativa, pues a mediados de 1944 ocurrió un conato de rebelión militar y por corto tiempo el ejército tomó el poder en Ibagué $^{32}$. No obstante esa opinión de sosiego, la política colombiana se tornó violenta: [...] el ambiente de las relaciones interpartidarias en el periodo comprendido entre 1930-1945 estaba lejos de ser el de una arcadia feliz ${ }^{33}$. De allí que desde 1930 el Tolima empezó a experimentar rencillas políticas entre liberales y conservadores, que involucraron a actores políticos más recientes, particularmente a los socialistas y comunistas $^{34}$. Respecto a la criminalidad, aunque expresaban una preocupación por la vagancia, las raterías y el bandidaje, los gobernantes locales también creían que la percepción del crimen era infundada y que esa sensación de inseguridad traía consecuencias nocivas. De este modo lo manifestó el gobernador Mariano Serna: Es de lamentar que se conceda tanta importancia al comentario de los actos delictivos de los ciudadanos y al trazado de diez mil hipótesis exageradas que producen desconfianza y malestar ${ }^{35}$.

Otro tanto ocurrió con las expectativas en torno a la policía. Aunque desempeñaba diversas funciones, se esperaba de ella que sobre todo detuviera a las bandas organizadas

\footnotetext{
${ }^{29}$ Astrid Liliana Sánchez Mejía, Entre el control de la criminalidad y el debido proceso. Una historia del proceso penal colombiano (Bogotá: Pontificia Universidad Javeriana, 2017), 60.

${ }^{30}$ Por política criminal se puede entender — atendiendo los postulados del positivismo penal— "la acción del Estado contra el crimen, conforme a los resultados de la investigación criminológica entendida como ciencia empírica". Eugenio Raúl Zaffaroni, Tratado de derecho penal. Parte general (Buenos Aires: Ediar, 1998), 149-150.

${ }^{31}$ Rafael Dávila, Mensaje del Gobernador del Departamento a la Asamblea del Tolima en sus sesiones ordinarias de 1925 (Ibagué: Imprenta Departamental, 1925), 7-8; Félix María Reina, Mensaje del Gobernador del Departamento a la Asamblea del Tolima en sus sesiones ordinarias de 1930 (Ibagué: Imprenta Departamental, 1930), 4; Gonzalo Sánchez Gómez, Los bolcheviques del Líbano (Tolima): crisis mundial, transición capitalista y rebelión rural en Colombia (Bogotá: Ecoe, 1981).

${ }^{32}$ Ricardo Bonilla Gutiérrez, Mensaje del Gobernador del Departamento a la Asamblea del Tolima en sus sesiones ordinarias de 1925 (Ibagué: Imprenta Departamental, 1925), 5.

${ }^{33}$ Medófilo Medina, "Algunos factores de violencia en el sistema político colombiano, 1930-1986", Anuario Colombiano de Historia Social y de la Cultura, 13-14 (1985-1986): 283.

34 Tribunal Superior de Ibagué, "Sumario contra Simón Rubiano, Manuel Antonio Camacho y otros, por el homicidio de Santos Padilla” Ibagué, 1941, Archivo Histórico de Ibagué (AHI), Ibagué, Sección República, Fondo Criminales.

${ }^{35}$ Mariano Melandro Serna, Mensaje del Gobernador del Departamento a la Asamblea del Tolima en sus sesiones ordinarias de 1941 (Ibagué: Imprenta Departamental, 1941), 14.
} 
$\mathrm{y}$, hasta cierto punto, pudo cumplir con este objetivo. Los gobernadores liberales exigieron el restablecimiento de la guardia montada para detener a los cuatreros y malhechores, como lo solicitó en 1935 el gobernador Rafael Parga a la Asamblea Departamental $^{36}$. Otros gobernadores hicieron la misma exigencia al gobierno nacional, justificándose en el alto costo que representaba para las finanzas del Tolima reducir a las cuadrillas y bandas criminales. Así ocurrió con la operación para capturar al conocido bandido Reinaldo "El Palomo" Aguirre, pues la redada requirió un alto número de efectivos que fueron desplegados en los municipios de Honda, Mariquita, Fresno y Herveo. Entonces, todo apuntaba a que la policía era el caballo de batalla de la política de seguridad de los liberales, quienes solicitaron año tras año recursos para aumentar los efectivos policiales que se destinarían, sobre todo, a remediar los efectos nocivos de las bandas dedicadas al abigeato ${ }^{37}$.

Este artículo toma en cuenta tres variables de la criminalidad. Examina el número de los sindicados por el delito del abigeato, los sindicados por homicidio y el total de los sindicados por todos los delitos ${ }^{38}$. Gracias a las estadísticas criminales en las que se basa este artículo ${ }^{39}$, es posible afirmar que los coeficientes de correlación entre las variables del Tolima y las variables equivalentes del nivel nacional, durante el quindenio, son muy altos. En el caso del abigeato, el coeficiente de correlación es de 0,91; el coeficiente para el homicidio es de 0,79; y para la cifra de sindicados es de 0,90. Por lo tanto, se arguye que los ciclos de la criminalidad tolimense eran un reflejo de la dinámica de la criminalidad que ocurría en el país. En el mismo sentido, se han referenciado bienios clave en la historia del orden nacional y departamental (para el abigeato y el homicidio corresponden los bienios 1924,$1925 ; 1937,1938 ; 1940,1941 ; 1947,1948$ y para el total de sindicados se añadió el bienio 1953,1954), para extraer de allí los indicadores de la criminalidad. Esta selección se ha realizado en vista de la ausencia de series completas de datos estadísticos; sin embargo, dichos cortes permiten afirmar que los niveles de criminalidad no fueron tan elevados para la década de 1930 y la primera mitad de la siguiente década, pues si se miran con detenimiento dichas cifras, a mediados de los treinta es evidente que los indicadores de los homicidios y del abigeato tendieron a estabilizarse e incluso disminuyeron.

La Gráfica 1 muestra que el delito de abigeato —el que mayor preocupación despertaba entre la población y las autoridades tolimenses - no se incrementó en la magnitud referida por los pobladores que se quejaron ante la justicia local. Los picos más

\footnotetext{
${ }^{36}$ Rafael Parga, Mensaje del Gobernador del Departamento a la Asamblea del Tolima en sus sesiones ordinarias de 1935 (Ibagué: Imprenta Departamental, 1935), 12.

${ }^{37}$ Este tipo de organización criminal, dedicada al robo, al pillaje y a las tropelías formará parte de una de las tipologías mediante las cuales la historiografía política presenta el bandolerismo como criminalidad típica de la violencia política desde 1960. María Victoria Uribe A., Matar, rematar y contramatar: las masacres de la violencia en el Tolima 1948-1964 (Bogotá: Cinep, 1978), 52.

${ }^{38} \mathrm{El}$ sindicado es aquella persona que se encuentra en condición de denunciado, ante la justicia penal, por cometer algún delito. Es así que las estadísticas criminales se basan el número anual de sindicados, bien sea que sus procesos estén en la etapa condenatoria, absolutoria o de sobreseimiento.

${ }^{39}$ Los datos se extraen de los anuarios de estadística de Colombia y del Tolima. Se advierte que hay datos incompletos, pues no siempre los departamentos informaron al nivel central las cifras para elaborar los resúmenes anuales. Además, en este estudio se prefirió la cifra combinada de presos y sindicados, por lo que dicha combinación permite tener datos constantes en treinta años (1924 a 1954).
} 
altos en este delito se registraron a nivel nacional para los bienios 1924-1925 y 19471948, debido probablemente a las consecuencias de la crisis económica nacional de la década del veinte y al aumento de la violencia política al finalizar la década de 1940. La disminución de este delito en todo el país fue notable en el bienio 1937-1938, si se mira respecto de los niveles alcanzados en la década anterior. Si bien es cierto que en el caso del Tolima los indicadores del abigeato aumentaron, no lo hicieron de manera exponencial; el crecimiento delincuencial pudo haber sido contenido por la entrada en vigencia de los códigos penal, de procedimiento penal y de policía para la nación y el departamento entre 1937 y 1938. Aun así, el crecimiento del abigeato en el bienio 19401941 obedeció a un recrudecimiento de las acciones de las bandas delictivas como la que comandó el Palomo Aguirre.

Figura 04. Comparativo de los sindicados por abigeato, Tolima y Colombia (19241948)*

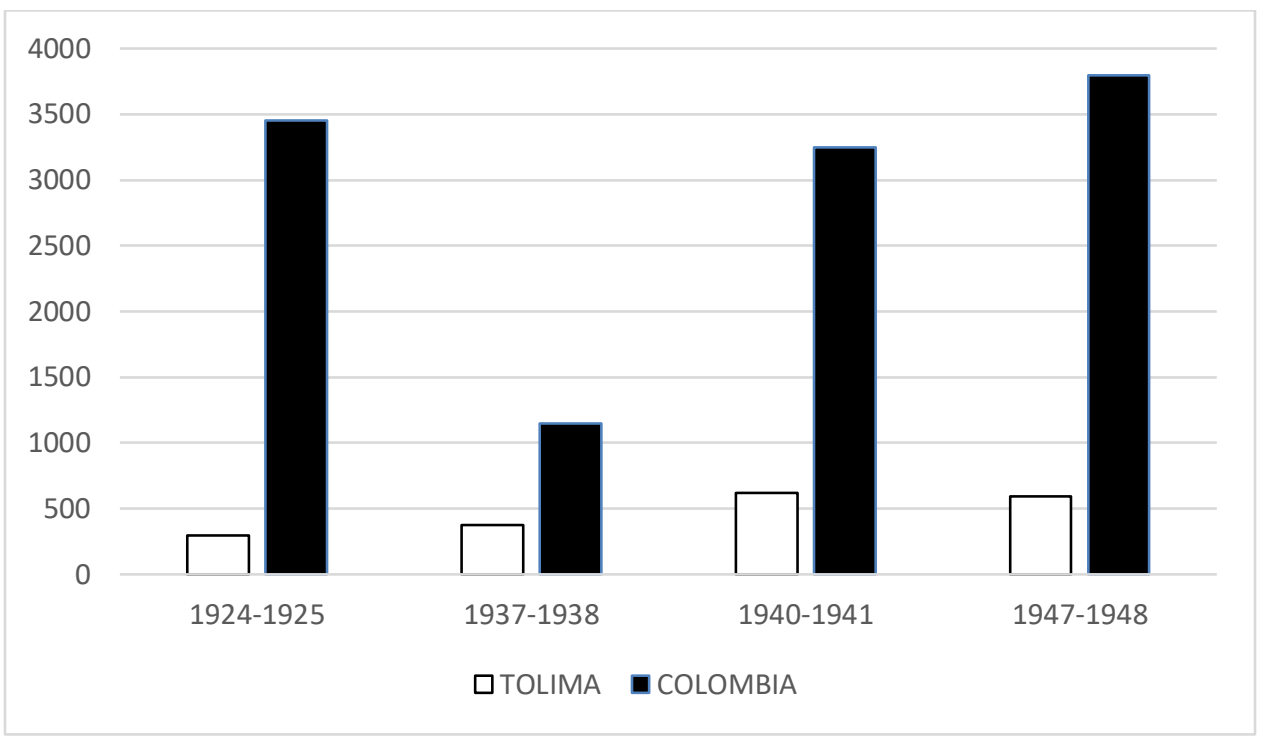

\footnotetext{
* Proporción de las denuncias por abigeato a nivel nacional y departamental. Elaboración propia a partir de la revisión del Anuario estadístico del Tolima (Ibagué), 1935-1945 y del Anuario general de Estadística (Bogotá), 1924-1954.
}

La Gráfica 2 evidencia que la criminalidad se estabilizó en la década de 1930 y, más aún, que disminuyó en lo que respecta al delito de homicidio. Llama la atención que en el Tolima, durante el bienio 1947-1948, el incremento en este delito no fue equivalente al del nivel nacional, ya que los registros por muertes violentas permanecieron estables, incluso después de la muerte del líder liberal Jorge Eliécer Gaitán el 9 de abril de $1948^{40}$, pero pocos años después se produjo un significativo aumento como lo muestra un estudio

\footnotetext{
${ }^{40}$ El número aproximado de muertes violentas en 1950 superó las 50.000; y el lugar donde más se produjeron esos homicidios fue en el Tolima. Carlos Miguel Ortiz Sarmiento, Estado y subversión en Colombia. La violencia en el Quindío, años 50 (Bogotá: Cerec/Cider, 1985), 23.
} 
realizado en $2003^{41}$. No obstante, es posible que las cifras hayan sido depuradas por el régimen conservador o que muchas muertes violentas jamás se denunciaron. Lo que se puede decir es que la política criminal de los liberales fue exitosa para controlar la criminalidad durante el bienio 1937-1938.

Figura 05. Comparativo de los sindicados por homicidio, Tolima y Colombia (1924-1948)*

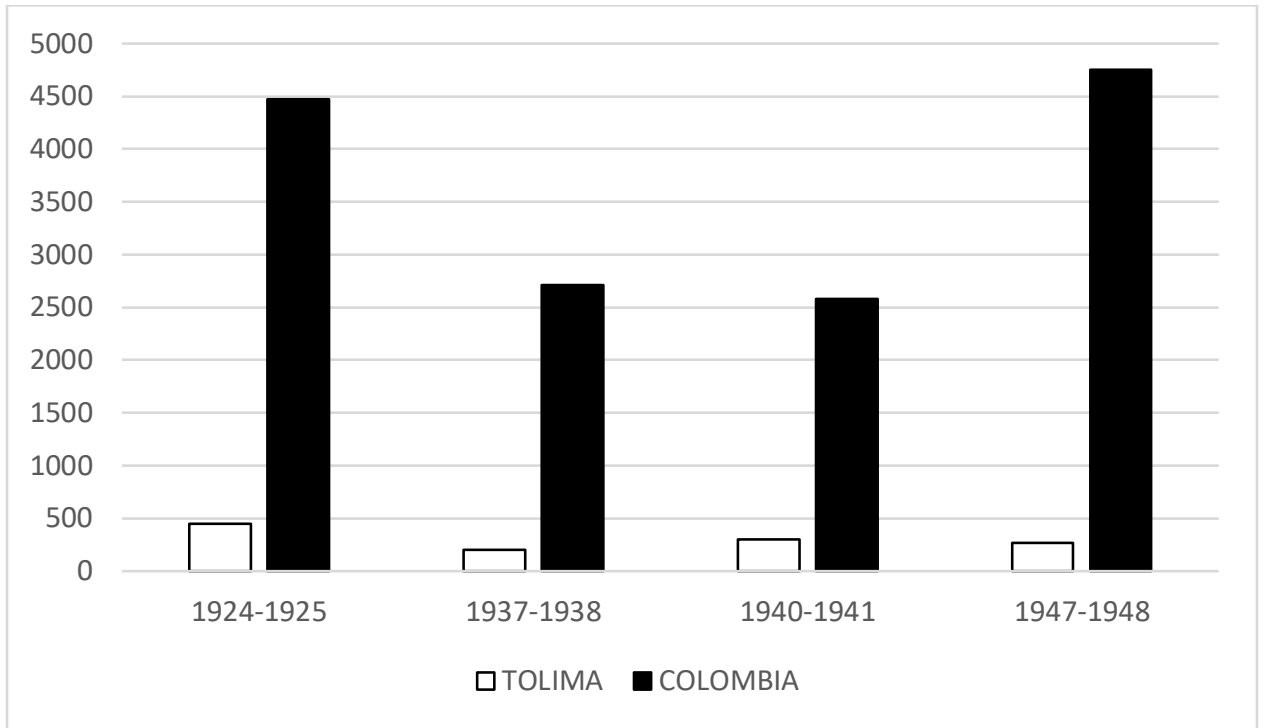

* Proporción de las denuncias por homicidio a nivel nacional y departamental. Elaboración propia a partir de la revisión del Anuario estadístico del Tolima (Ibagué), 1935-1945 y del Anuario general de Estadística (Bogotá), 1924-1954.

La Gráfica 3 indica la variación en la cantidad de sindicados en el Tolima y Colombia durante cinco bienios y muestra cómo a mediados de la República Liberal esa cantidad disminuyó y logró estabilizarse a inicios de los años cuarenta. La disminución en los indicadores de los sindicados reflejó la política criminal impulsada por los liberales, lo que se comprueba con el hecho de que el punto más bajo haya sido el del bienio 19371938. Estos niveles inferiores se mantuvieron hasta el bienio 1940-1941 y se dispararon ostensiblemente para el bienio 1953-1954 ${ }^{42}$, cuando ya estaba en marcha la política de pacificación de la dictadura militar que pretendía poner fin a la violencia política de esos años.

De otra parte, para entender las gráficas vale aclarar que durante los años treinta los gobiernos liberales pusieron en práctica un paquete de medidas como la "ciudad por cárcel" o arresto domiciliario, el pago de multas, trabajos públicos y el confinamiento en colonias penales que ayudaron a disminuir no solo el delito en general, sino el número de

\footnotetext{
${ }^{41}$ El estudio argumenta que en 1946 la tasa de homicidios era bastante baja, y en departamentos como el Tolima fue inferior a 12.0 por cada 100.000 habitantes; pero en 1956 llegó a 167 por cada 100.000. Esa tasa de homicidios creció exponencialmente en el Tolima, ya que pasó de 8.5 por cada 100.000 habitantes en 1946 a 86.7 en 1952. Fabio s, Ana María Díaz y Michel Formisano, "Conflicto, violencia y actividad criminal en Colombia: un análisis espacial”, Documentos Cede (Universidad de los Andes) 002187 (2003): 7 y 45 .

${ }^{42}$ Este análisis del total de sindicados se extiende a otro bienio (1953-1954) debido a la existencia de datos y para enfatizar el alza de la criminalidad en los años cincuenta.
} 
sindicados que iban a la cárcel; también esa política complementó los códigos tendientes a prevenir la criminalidad. Pese a ello, la impunidad era muy alta, debido en parte a que la policía tenía limitaciones para dar captura fuera del radio del área local y porque, desde el punto de vista judicial, muchos casos eran sobreseídos, es decir, no llegaban a una conclusión por la ausencia de elementos probatorios.

\section{Figura 06. Comparativo del total de sindicados, Tolima y Colombia (1924-1954)*}

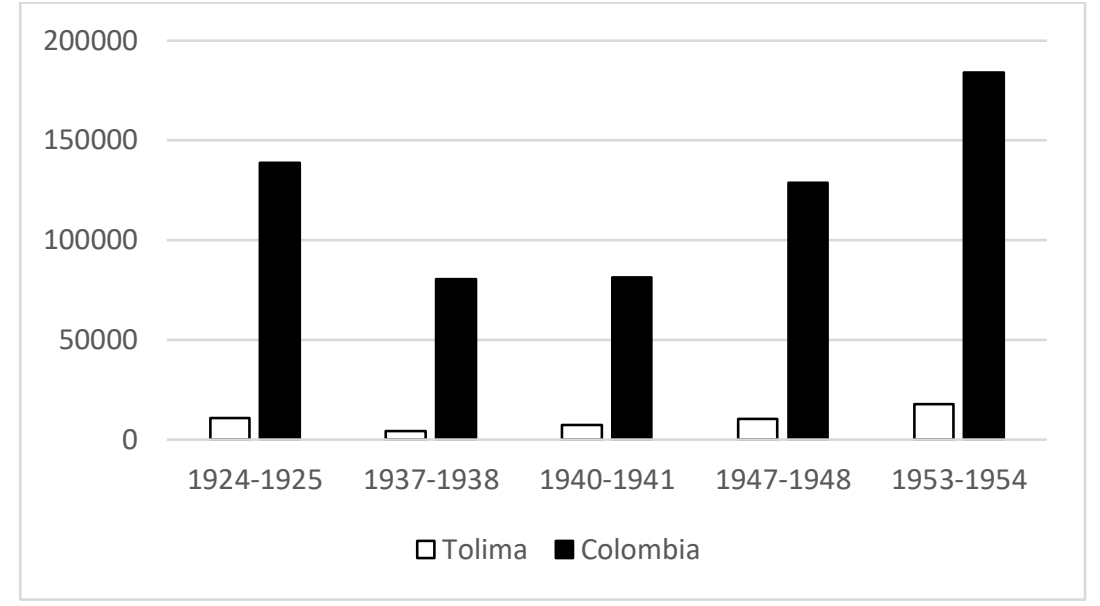

*Variación entre el número de presos y sindicados en el país en comparación con los datos departamentales. Elaboración propia a partir de la revisión del Anuario estadístico del Tolima (Ibagué), 1935-1945 y del Anuario general de Estadística (Bogotá), 1924-1954.

Por tanto, los números parecen confirmar que la criminalidad no creció en las dimensiones que la opinión pública había supuesto, pero esta percepción contribuyó a generar políticas más violentas que el delito a reprimir; entonces, se entiende, por ejemplo, que ultimar a los cuatreros se justificaba con la ausencia de un aparato estatal fuerte que impidiera la impunidad y con que los bandidos ponían en peligro la economía de las familias que dependían de los cultivos y la ganadería ${ }^{43}$. Así que las víctimas del abigeato adquirían el estatus legal de policías para hacer justicia por mano propia. Dichas prácticas violentas, que tendieron a controlar el crimen durante la República Liberal, reaparecerían en la violencia en la década de los cincuenta ${ }^{44}$.

\section{Los perpetradores y las víctimas de la criminalidad tolimense}

La descripción de los delincuentes que operaban en el Tolima remite a una población flotante, de mayoría masculina, de menores de veinticinco años, solteros, analfabetas, que

\footnotetext{
${ }^{43}$ Uno de los elementos constituyentes de la sociedad campesina es la economía aldeana y el sistema de valores que de ella surge y que comprende un conjunto de derechos y obligaciones comunitarios. Marco Palacios, ¿De quién es la tierra? Propiedad, politización y protesta campesina en la década de 1930 (Bogotá: FCE/Universidad de los Andes, 2011), 82.

${ }^{44}$ Este tipo de acciones pueden ser vistas bajo el lente de lo que E. P. Thompson denominó "Economía moral”. E. P. Thompson, La economía moral de la multitud y otros ensayos (Bogotá: Ediciones Desde Abajo, 2014).
} 
tendían a ocuparse en los oficios de peón y campesino ${ }^{45}$, proclives al baile, a la juerga, al concubinato y al consumo del alcohol y de otras sustancias psicoactivas. Uno de los perfiles de perpetrador escogido para apoyar tal descripción fue el de un hombre de baja estatura, complexo y de tez morena, católico, de edad madura y natural de Guatavita, de oficio campesino y jornalero. Su nombre Marcos García, acusado de uxoricidio.

De un ladrón de ganado, Filomeno Oviedo, se decía que era un hombre errante, [que] se quedaba en cualquier parte y siempre en las cocinas [además] le gustaba mucho la coca. El padre declaró ante el juez que su hijo Filomeno, una vez había abandonado el hogar paterno, se volvió un ratero de los más finos ${ }^{46}$. El temor que inspiraba Filomeno entre los campesinos no permitía alguna delación. De hecho, los hombres que fueron comisionados para atraparlo registraban antecedentes penales por contrabando; de otro de ellos se dijo que padecía sífilis y un tercero fue interrogado para que declara si en su familia había casos de locos, dementes o cretinos.

El proceso de la muerte de Oviedo describe un panorama social de concubinatos, promiscuidad y felonía. Mercedes González había sido la concubina de Oviedo, y vivía en la casa donde él fue muerto mientras visitaba a la hija que habían tenido los dos. Aunque González no vivía con Oviedo y mantenía tratos frecuentes con él, afirmó que Oviedo la había perjudicado y que de ese hecho había nacido la niña que ahora Filomeno pretendía arrebatarle, que iba en compañía de un secuaz, que la molestaba, y sostuvo que como le dijera que no me gustaba su persona, me iba a disparar con una escopeta ${ }^{47}$.

En otros casos, familias completas fueron denunciadas por homicidio y hurto. Lo cual puede ser una muestra de qué tan fuertes eran los vínculos del grupo que los empujaba a delinquir para prolongar su forma de vida económica. Lo que también revela la documentación judicial es el surgimiento de bandas organizadas en la década de 1930 (un aspecto del bandidaje social) cuyo accionar resurgiría como una característica más generalizada de la violencia en décadas posteriores ${ }^{48}$. Los asaltantes actuaron en cuadrillas que sustraían los cargamentos que transportaba la compañía del cable aéreo que comunicaba al Tolima con Caldas y armaron una artimaña para conocer los pormenores de la compañía. De suerte que se engancharon como empleados en esa empresa para cometer los hurtos sin despertar mayores sospechas. Debido a la frecuencia de este delito, la compañía dispuso una ronda de celadores que viajaban en parejas en las vagonetas para custodiar los cargamentos. Esta forma de inspección también tenía como propósito descubrir a los asaltantes, a los cómplices y a los encubridores que trabajaban como operarios en The Dorada Railway Company Limited, llamada popularmente El Ferrocarril de la Dorada. En mayo de 1933 el inspector de los cargamentos, Gabriel Chávez, recibió un disparo mortal cuando se desplazaba en una vagoneta a la ciudad de Manizales. El atentado tuvo lugar en el municipio de Fresno en horas de la mañana y

\footnotetext{
${ }^{45}$ Dirección Nacional de Estadística, Anuario general de Estadística (Bogotá: Imprenta Nacional, 1940): 341.

46 Tribunal Superior de Ibagué, "Sumario contra Juan Moreno, Evilario Ospina y otros por homicidio", Ibagué 1939, AHI, Ibagué, S. República, F. Criminales, f. 24 anverso.

47 Tribunal Superior de Ibagué, "Sumario contra Juan Moreno, Evilario Ospina y otros por homicidio", Ibagué 1939, AHI, Ibagué, S. República, F. Criminales, f. 24 anverso.

48 Sánchez y Meertens, 29.
} 
algunos testigos identificaron a siete hombres como los autores del homicidio. Antes de este hecho, los presuntos homicidas habían sido despedidos de The Dorada por órdenes de Chávez. Días antes de su muerte, Chávez había denunciado a varias personas por el robo continuado de la carga del cable en la jurisdicción de Mariquita. La denuncia desveló una banda compuesta por más de una decena de hombres y mujeres pertenecientes a una misma familia, que se ocupaban de sustraer mercancías del cable con la complicidad de algunos empleados de la compañía. Las averiguaciones por este hurto continuaron después de la muerte del jefe de celadores Gabriel Chávez. En efecto, tras la denuncia fueron vinculados al juicio Teodora Reyes y su hijo, Misael González, también el hermano de Teodora, Hermógenes, lo mismo que otros dos de sus familiares. A esos delincuentes, la historiografía local les ha añadido la semblanza del delincuente social, "el gran delincuente" o el bandido que asaltaba el cable aéreo y parecía tener el don de la ubicuidad $^{49}$. Al margen de la idealización del bandido social queda claro que este fenómeno criminal ya estaba presente en la región antes de la movilización de las guerrillas y de los bandidos en tiempos de la Violencia.

Para cerrar este caso, las autoridades judiciales supusieron que el homicidio de Chávez estuvo motivado por la desconfianza que despertó entre los empleados la presencia del inspector, pues se sabía que su viaje a Manizales tenía como finalidad remover a varios trabajadores sospechosos de participar en el robo de café y otras mercancías. Esta conjetura provino de una serie de cartas que escribió Chávez a sus superiores en las que informó sobre el miedo que sentía de ser víctima de un atentado proveniente de algunos trabajadores resentidos. Finalmente, el Tribunal cerró el caso por sobreseimiento, pues según el juez, no existió prueba de naturaleza suficiente conforme a la ley para enjuiciar a algún sindicado en la muerte del inspector del cable ${ }^{50}$.

La actuación delictiva de estas bandas se basaba en una organización más o menos horizontal, cuya jefatura dependía de la trayectoria criminal o del carisma del líder. Estos grupos compartían un lenguaje cifrado que consistía en el uso de alias, señas y claves para engañar a las víctimas y para esquivar los cercos de la policía. Las bandas dedicadas al robo de ganado, una vez sustraído, procedían bien sea a distribuirlo entre la parentela o a venderlo en sitios alejados del lugar del robo, casi siempre a unos dos días de camino. Las bandas que hurtaban mercancías contactaban con antelación a los compradores y reducidores; estas operaciones de comercio ilícito se daban con mayor frecuencia con los cargamentos de café.

En la década de1930 se habló de una ola "atroz" de robos, ultrajes y abusos de los que fueron víctimas sobre todo mujeres. Uno de los primeros casos fue la denuncia de María Teresa Perdomo, víctima de maltratos de su compañero Marcos García. El día 20 de marzo de 1937, en la población de Lérida, Perdomo fue enviada a vender una arroba

\footnotetext{
49 Eduardo Santa, "Palomo Aguirre: el bandido que asaltaba el cable más largo del mundo", Revista Credencial Historia, 158 (febrero, 2003), consultado 14 de marzo de 2018, https://www.banrepcultural.org/biblioteca-virtual/credencial-historia/numero-158/palomo-aguirre-elbandido-que-asaltaba-el-cable-mas-largo-del-mundo

${ }^{50}$ Tribunal Superior de Ibagué, "Sumario. En averiguación del responsable o responsables del delito de homicidio con caracteres de asesinato perpetrado en la persona de Gabriel Chávez, el día 22 de mayo de 1933”, Ibagué, 1933, AHI, Ibagué, S. República, Fondo criminales, f. 138 verso.
} 
de arroz y la lluvia le impidió regresar en el lapso fijado por García ${ }^{51}$. Los motivos de García para abusar de Perdomo quedaron consignados en los autos judiciales como de poca importancia; se redujeron a las sospechas infundadas que tenía el jornalero del comportamiento de Teresa, pues creía que ella había tenido encuentros con amantes. El alegato de Teresa consistió en argumentar que las condiciones del estado del tiempo (la lluvia pertinaz) le impidieron regresar temprano y la obligaron a "arrimarse" a la casa de los vecinos. Infortunadamente para Teresa, fue sorprendida por García en la casa de un hombre; García la golpea en el rostro y la amenaza con someterla a un castigo ejemplar. En efecto, esa noche la obliga a cocinar y luego la amarra de las piernas, la desnuda, la cuelga boca abajo de una viga, la azota, la hiere de gravedad y lacera sus genitales. En la madrugada, ella escapa como puede a la casa de sus tíos, quienes la acompañan a la alcaldía a denunciar a Marcos García.

El atacante es conducido ante el juez y niega los hechos; es compelido a no agredirla de nuevo y es multado, por lo que ambos, víctima y victimario, regresan a su lugar de residencia. Una vez en su casa, García lanza improperios contra Teresa, la golpea, la lanza al suelo e intenta ahorcarla con sus manos. El hecho es visto por un vecino que los observa, grita para intimidar a García y pide ayuda de la policía que recaptura al agresor. Como desenlace, la mujer fallece a los pocos días de esta nueva agresión y a Marcos se le abre un proceso por uxoricidio. La víctima era una mujer de unos cuarenta años, que trabajaba en diversos oficios del campo, cocinaba y lavaba la ropa; además vivía en ilicitud marital y trabajaba la tierra en calidad de arrendataria.

Finalizando la década de 1920, se denunció en la ciudad de Honda la violencia sexual que sufrió una adolescente al interior de su propia casa, ubicada en las goteras de la ciudad. Para la época, ese delito correspondía a los tipos penales de fuerza y violencia, y corrupción y causó revuelo entre los hondanos, tanto que fue calificado como algo verdaderamente abominable por dos razones. La primera razón $-\mathrm{y}$ tal vez la más importante - fue la participación de la madre de la víctima como cómplice, pues motivada por la promesa de una compensación económica sujetó a su hija mientras era violada. La segunda porque el acusado era una persona de renombre en la ciudad; se trataba de un hombre de negocios oriundo de Barranquilla, tan influyente que supo mover los hilos del poder a su favor. La madre de la víctima, Betsabé Herrera, era de extracción humilde, vivía sola con su hija en una casa en condiciones precarias y se dedicaba al oficio de lavandera. La abusada, Irene Herrera, era una adolescente de catorce años que tenía retardo cognitivo, por lo que se le nombró un curador ad litem quien la representó en algunas etapas del proceso.

El delito fue puesto en conocimiento de la justicia cuando una vecina denunció que, durante una noche, escuchó quejidos que provenían de una casa cercana y junto con otra mujer observaron cómo el abusador accedía a la menor; por lo que testificó lo siguiente: me asomé por los claros de los balsos de la casa y vi al señor Manuel Domingo

\footnotetext{
${ }^{51}$ Tribunal Superior de Ibagué, “Causa contra Marcos García por homicidio y heridas”. Ibagué, 1939, AHI, Ibagué, S. República, F. Criminales.
} 
Suárez haciendo uso de la muchacha porque estaba encima de ella y la madre teniéndole los pies ${ }^{52}$.

El juicio se prolongó por varios años ya que Suárez, escudado en su poder económico, se hizo a los servicios de un abogado que asumió una estrategia agresiva durante todo el proceso. Circunstancias extrañas acompañaron el juicio y tendieron a mejorar la situación del abusador; una de ellas fue la sustracción del sumario cuando hacía tránsito del Juzgado Especializado al Tribunal Superior de Ibagué. Otros aspectos oscuros fueron la intervención de testigos cercanos al implicado que gozaban de poder político, como el testimonio del hermano del secretario de la Gobernación del Tolima. Este abogado afirmó que la noche del delito Suárez lo acompañó durante toda la noche en una cena de negocios. Además la cómplice, pese a su pobreza, logró tener un fiador solvente quien pagó una suma considerable como fianza para que accediera a la libertad condicional y le contrató un abogado. Cuando la apelación llegó al Tribunal, las testigos que denunciaron el delito fueron intimidadas por sujetos extraños y se presentaron otras personas que ahora testificaban que las primeras habían puesto el denuncio movidas por venganza contra la madre de la abusada.

Este caso enseña aspectos culturales y sociales que sobresalen al momento de aceitar los engranajes del aparato de la justicia. Uno de ellos son los lugares de sociabilidad de las clases marginadas; dado que fue necesario hacer una ampliación de las indagaciones de las denunciantes, salieron a flote situaciones que al inicio no tuvieron importancia. La información se refería al abuso sexual como estrategia de supervivencia económica, pues la cómplice justificó el trato sexual de su hija con Suárez, en razón de que el abusador se comprometía a paliar la pobreza de las dos mujeres con ropa y comida. Esta información se difundió entre las mujeres que acudían al lavadero, en la orilla del río, y la fuerza del rumor se logró filtrar en las pruebas testimoniales. Así operó un recurso de las mujeres marginadas —el escándalo - para enfrentar la arbitrariedad de los poderosos. La otra cara de la moneda fue la manera en que la corrupción perforó la objetividad judicial, pues este caso fue salpicado por artilugios dilatorios de los términos, la adulteración de las piezas procesales, el soborno de los peritos, la manipulación de algunas pruebas y la alusión a hechos extrajurídicos; todo tendiente a desvirtuar la indefensión de Irene respecto de su violador.

Es de subrayar la manipulación de las menores de edad, obligadas por sus padres a sostener relaciones sexuales con adultos, con la esperanza de lograr un casamiento. Sin embargo, no en todos los casos se fallaba a favor de la parte denunciante, puesto que durante el juicio era necesario probar que el abuso de menores les había ocurrido a adolescentes de buenas costumbres morales y preferiblemente vírgenes ${ }^{53}$. Así, la Sala Penal del Tribunal Superior dejó sin efectos un fallo proferido por el Juzgado Segundo Superior del Distrito que condenaba a Anatolio Nungo por corruptor de menores en el municipio de Piedras; el argumento en que se basó la sentencia derogatoria fue el

\footnotetext{
52 Tribunal Superior de Ibagué, "Causa contra Manuel Domingo Suárez y Betsabé Herrera por el delito de fuerza y violencia, y corrupción”, Ibagué, 1928, AHI, S. República, F. Criminales, f. 6 anverso.

${ }^{53}$ Ortega Torres, Código penal, 235.
} 
testimonio de un vecino que dio fe del supuesto comportamiento lascivo de la menor: Después de grande (al cumplir once años) varias noches que eso era un rochelo hasta la una de la mañana con hombres ahí en esa casa, jugando pegas y escondidijos y a ese juego que llaman borugo que corretean de una parte y otra, esto lo vi por multitud de veces, unas veces detrás de los hombres y otras veces de huida de los hombres ${ }^{54}$. Estos ejemplos reiteran el grado de sujeción que sufrían mujeres y niños, pues durante los procesos padecían desventaja física y jurídica respecto de sus maridos, padres y abusadores. Respecto de las mujeres abusadas, los datos hacen mención a que en su mayoría eran criadas o empleadas menores de 18 años. Por último, este tipo de violencia sexual proliferaba en el departamento del Tolima (Ver figura 07).

\section{Figura 07. Homicidios, delitos sexuales y políticos, Tolima (1930-1945)*}

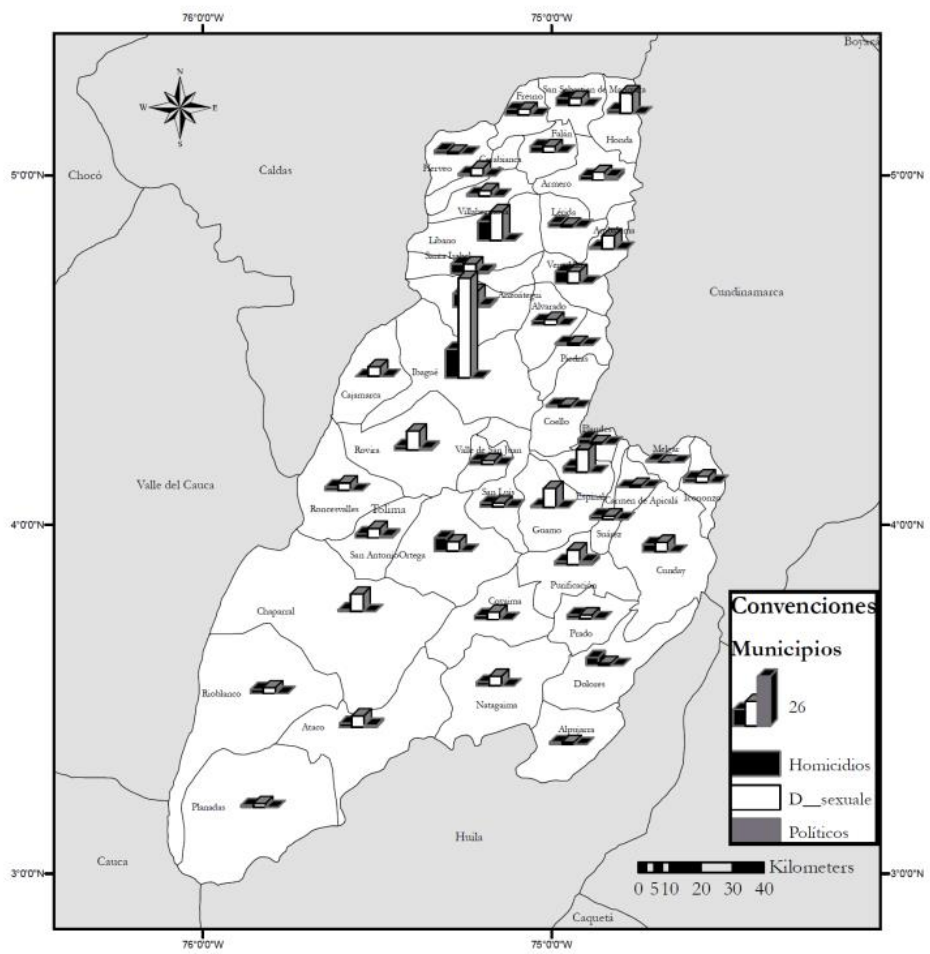

* Distribución de los delitos sexuales, políticos y homicidios por municipios en el Tolima, entre 1930 y 1945. Las cantidades corresponden a los fallos de última instancia proferidos por el Tribunal Superior de Ibagué. Elaboración propia con base en las series recopiladas en el Archivo Histórico de Ibagué (AHI).

\section{Conclusión}

La investigación presentada ha procurado controvertir la idea de un aumento de la criminalidad en el Tolima durante la República Liberal. Lo anterior no significa negar los hechos objetivos de la criminalidad, lo que se replantea es su percepción. En este sentido, el número de delitos violentos que formaron una imagen de criminalidad creciente

\footnotetext{
${ }^{54}$ Tribunal Superior de Ibagué, "Se revoca el auto de enjuiciamiento apelado y en su lugar se sobresee definitivamente a favor de Anatolio Ñungo del cargo de corruptor de menores”. Crónica Judicial (s. d.) (1941): 1075.
} 
durante el quinquenio de 1930 a 1945 es comparativamente inferior respecto de las décadas de 1920 y 1950. La sensación de una escalada criminal cundió sobre todo entre la población que fue víctima del abigeato y logró trascender a los oídos del Gobierno departamental. Sin embargo, los gobernadores aunque fueron escépticos acerca de esa oleada criminal, se sirvieron de ella para exigir recursos al Gobierno central.

Algunas modalidades de crímenes violentos cometidos en el Tolima durante la Republica Liberal fueron mucho más notorias en la década de 1950. Al observar esas pautas delictivas con detenimiento, se pudo establecer que obedecían hasta cierto punto a costumbres o valoraciones culturales toleradas en el seno de la comunidad. Lo anterior responde a por qué las bandas de cuatreros pudieron moverse con relativa facilidad y evitaron con éxito el cerco de la justicia.

El recurso a la violencia aneja al crimen parece que constituía un mecanismo para mantener el statu quo dentro del grupo social, pero también se acudió a la violencia criminal para resolver las necesidades económicas en un complejo marco de relaciones sociales y de dependencias mutuas. Estas relaciones se reconfiguraron constantemente en los años treinta y pudieron estar mediadas por comportamientos ilícitos. Como una época de cambio, la década de 1930 significó la aceleración de la urbanización del país y desde las ciudades se remodelaron las ideas del delito, que se ajustaron al ideario proveniente de Europa. De modo que existían dos ámbitos de entendimiento de la criminalidad, uno, la reconocible cultura que toleraba ciertos delitos en el campo y que tenía que ver con un trasfondo moral, que también era un aspecto económico y social vital; las autoridades judiciales, por su parte, emplearon formas científicas para controlar la delincuencia sin importar demasiado el contexto cultural en que se producía.

Este estudio de los victimarios, las víctimas, las autoridades y la justicia penal revela cuán profundos eran los vínculos sociales, en especial los de la sociedad campesina, y cómo esas formas atávicas pervivieron incluso en las ciudades. Dentro del tipo de pautas constantes entre el mundo rural y el urbano sobresalieron las violaciones a la propiedad privada, el chisme y la familiaridad entre vecinos. Como se ha notado, los comportamientos criminales eran admitidos por el grupo cuando su existencia dependió del hurto o del bandidaje; también algunas prácticas sexuales fueron alentadas por las familias, aunque reprimidas por el Gobierno liberal.

El tipo de estudio planteado aquí permitirá a futuro entender las estructuras violentas del crimen y discutir las explicaciones que sobre la violencia ha dado la historiografía política, y determinar qué aspectos del delito son constantes o eventuales en una época. Por lo pronto, afloran dos maneras de entender el problema: de un lado está la visión del delito y la violencia como componentes culturales del mundo campesino y, del otro, la perspectiva científica del derecho que ha catalogado a las clases desposeídas como las únicas fuentes del crimen y la violencia. 


\section{Fuentes bibliográficas}

\section{Manuscritos}

Archivo Histórico de Ibagué, Ibagué (AHI), Sección República, Fondo Criminales

\section{Impresos periódicos}

Anuario estadístico del Tolima (Ibagué) 1935-1945.

Anuario general de Estadística (Bogotá) 1924-1954.

Crónica judicial. Órgano del Tribunal Superior de Ibagué (Ibagué) 1941-1942.

\section{Otros impresos}

Amador, Heriberto. Mensaje del gobernador del departamento a la honorable asamblea en sus sesiones ordinarias de 1934. Ibagué: Imprenta Departamental, 1934.

Bonilla Gutiérrez, Ricardo. Mensaje del Gobernador del Departamento a la Asamblea del Tolima en sus sesiones ordinarias de 1925. Ibagué: Imprenta Departamental, 1925.

Dávila, Rafael. Mensaje del Gobernador del Departamento a la Asamblea del Tolima en sus sesiones ordinarias de 1925. Ibagué: Imprenta Departamental, 1925.

Departamento del Tolima. Código de Policía, 1935 (Ordenanza 30 de 1932). Ibagué: Imprenta Departamental, 1935.

Ortega Torres, Jorge. Código penal y de procedimiento penal. Con notas, concordancias, jurisprudencia de la Corte Suprema y del Tribunal de Bogotá y las últimas leyes complementarias. Bogotá: Librería Colombiana Camacho Roldán \& Cía., 1947.

Parga, Rafael. Mensaje del Gobernador del Departamento a la Asamblea del Tolima en sus sesiones ordinarias de 1935. Ibagué: Imprenta Departamental, 1935.

Reina, Félix María. Mensaje del Gobernador del Departamento a la Asamblea del Tolima en sus sesiones ordinarias de 1930. Ibagué: Imprenta Departamental, 1930.

Serna, Mariano Melandro. Mensaje del Gobernador del Departamento a la Asamblea del Tolima en sus sesiones ordinarias de 1941. Ibagué: Imprenta Departamental, 1941.

\section{Internet}

Santa, Eduardo. "Palomo Aguirre: el bandido que asaltaba el cable más largo del mundo". Revista Credencial Historia, 158 (febrero, 2003), consultado 14 de marzo de 2018, https://www.banrepcultural.org/biblioteca-virtual/credencial-historia/numero-158/palomoaguirre-el-bandido-que-asaltaba-el-cable-mas-largo-del-mundo.

\section{Fuentes secundarias}

Aguirre, Carlos. "Crime, Race, and Morals: The Development of Criminology in Peru 18901930". Crime, History \& Societies 2, n. ${ }^{\circ} 2$ (1998): 73-90. doi:10.4000/chs. 968

Deas, Malcolm y Fernando Gaitán Daza. Dos ensayos especulativos sobre la violencia en Colombia. Bogotá: Fonade / DNP, 1995.

Fajardo, Darío. Violencia y desarrollo (Transformaciones sociales en tres regiones cafeteras del Tolima, 1936-70). Bogotá: Fondo Editorial Suramérica, 1979. 
Fernández Labbé, Marcos. "Sangre por sangre: la retórica judicial y la veracidad documental como problema heurístico en las solicitudes de indulto". En Justicia, poder y sociedad en Chile: recorridos históricos. Eds. Tomás Cornejo C. y Carolina González U. Santiago: Ediciones Universidad Diego Portales, 2007, 219-240.

Guzmán, Germán, Orlando Fals Borda y Eduardo Umaña Luna. La violencia en Colombia. T. I y II. Bogotá: Aguilar / Altea / Taurus / Alfaguara, 2010.

Henderson, James. Cuando Colombia se desangró. Un estudio de la Violencia en metrópoli y provincia. Bogotá: El Áncora Editores, 1985.

Karl, Robert A. Forgotten Peace. Reform, Violence, and the Making of Contemporary Colombia. Oakland: University of California Press, 2017.

Medina, Medófilo. "Algunos factores de violencia en el sistema político colombiano, 19301986". Anuario Colombiano de Historia Social y de la Cultura, 13-14 (1985-1986): 281-297.

Narváez H, José Ramón. Historia social del derecho y de la justicia. México: Porrúa, 2007.

Oquist, Paul. Violencia, conflicto y política en Colombia. Bogotá: IEC / Biblioteca Banco Popular, 1978.

Ortiz Sarmiento, Carlos Miguel. Estado y subversión en Colombia. La violencia en el Quindío, años 50. Bogotá: Cerec / Cider, 1985.

Palacios, Marco. ¿De quién es la tierra? Propiedad, politización y protesta campesina en la década de 1930. Bogotá: FCE / Universidad de los Andes, 2011.

Palacios, Marco. Violencia pública en Colombia, 1958-2010. México D. F.: FCE, 2012.

Parada García, Gilberto Enrique. "Derecho, positivismo y sociedad. El caso de la Facultad de Derecho (1900-1940)". En Economía, Lenguaje, Trabajo y Sociedad. Colección del Sesquicentenario Universidad Nacional de Colombia. T. 1, 1/3. Eds. Estela Restrepo Zea y otros, 56-87. Bogotá: Universidad Nacional de Colombia, 2017.

Parada García, Gilberto Enrique. "La historicidad del delito en la manualística del derecho penal colombiano". Vniversitas vol. 67, n. 137 (nov. 2018). doi:10.11144/Javeriana.vj137.hdmp.

Sánchez, Fabio, Ana María Díaz y Michel Formisano. "Conflicto, violencia y actividad criminal en Colombia: un análisis espacial". Documentos Cede (Universidad de los Andes) 002187 (2003).

Sánchez Gómez, Gonzalo. Los bolcheviques del Líbano (Tolima): crisis mundial, transición capitalista y rebelión rural en Colombia. Bogotá: Ecoe, 1981.

Sánchez, Gonzalo y Donny Meertens. Bandoleros, gamonales y campesinos. El caso de la Violencia en Colombia. Bogotá: El Áncora, 2006.

Sánchez Mejía, Astrid Liliana. Entre el control de la criminalidad y el debido proceso. Una historia del proceso penal colombiano. Bogotá: Pontificia Universidad Javeriana, 2017.

Thompson, E. P. Agenda para una historia radical. Barcelona: Crítica, 2000.

Thompson, E. P. La economía moral de la multitud y otros ensayos. Bogotá: Ediciones Desde Abajo, 2014.

Tovar Pinzón, Hermes. La batalla de los sentidos. Infidelidad, adulterio y concubinato a fines de la Colonia. Bogotá: Universidad de los Andes, 2012.

Uribe A., María Victoria. Matar, rematar y contramatar: las masacres de la violencia en el Tolima 1948-1964. Bogotá: Cinep, 1978.

Zaffaroni, Eugenio Raúl. Tratado de derecho penal. Parte general. Buenos Aires: Ediar, 1998. 